\title{
Marx e a questão russa
}

\author{
Rafael Afonso da Silva ${ }^{1}$
}

Resumo: O objetivo deste trabalho é o estudo dos textos de Marx sobre a "questão russa". O artigo sustenta que esses textos devem ser lidos no contexto da análise marxiana das conseqüências, para a perspectiva socialista, da ascendência global do capital. Na reconstituição dos argumentos de Marx, o artigo procura destacar a singularidade de seu tratamento do objeto em questão, tratamento que evidencia uma rigorosa e crítica subsunção ao objeto, recusando a sedução de chaves explicativas universais.

Palavras-chave: Marx, socialismo, Rússia.

Abstract: The aim of this text is to study Marx's texts about the "Russian question". This article argues that those texts must be read into the Marx's analysis from consequences - for socialistic perspective - from global ascendance of the capital. In the reconstitution of the Marx's arguments, the article seeks to detach the singularity of the Marx's treatment of the question - treatment that makes evident a rigorous and critic subordination to the object, refusing the seduction of universal keys of explication.

Keywords: Marx, socialism, Russia.

Ao tempo de A ideologia alemã, Marx esperava que os antagonismos internos do capital deflagrassem processos revolucionários simultaneamente em todos os países dominantes no continente europeu, arrebentando o quadro operacional do sistema antes mesmo da generalização do modo de produção capitalista no terreno mundial. Mais ou menos uma década depois, ele reconhecia que essa possibilidade poderia não se concretizar se o capital encontrasse uma "saída" em sua ascensão continuada naqueles lugares em que a sociedade burguesa ainda estava em processo de desenvolvimento:

\footnotetext{
1 Mestre em Sociologia pela Universidade Estadual de Campinas (Unicamp).Correio eletrônico: limacamarada@hotmail. com 
A tarefa histórica da sociedade burguesa é o estabelecimento do mercado mundial, pelo menos em suas linhas básicas, e a produção baseada no mercado. Como o mundo é redondo, parece que isso já foi realizado com a colonização da Califórnia e da Austrália e a anexação da China e do Japão. Para nós, a questão difícil é a seguinte. A revolução no Continente é iminente e assumirá imediatamente caráter socialista. Não será necessariamente esmagada neste cantinho do mundo, visto que em um terreno muito mais vasto o desenvolvimento da sociedade burguesa ainda está em ascendência? (MARX, 1983, p. 347)

Essa ameaçadora perspectiva só poderia ser descartada no mesmo terreno de que ela brotava, isto é, no terreno das conseqüências histórico-sociais da ascendência global do capital. Talvez por isso Marx tenha se dado conta tão prontamente da importância da irrupção do movimento dos escravos nos Estados Unidos e do movimento dos servos na Rússia do ponto de vista da revolução socialista. Em janeiro de 1860, ele escreve a Engels:

Em minha opinião, as coisas mais importantes que estão acontecendo atualmente no mundo são, de um lado, o movimento dos escravos na América, iniciado com a morte de John Brown, e, de outro, o movimento dos servos na Rússia. (...) Assim sendo, o movimento "social" começou no Ocidente e no Oriente. Junto com a esperada derrocada da Europa Central, isso promete grandes coisas. (MARX, 1985, p. 4)

O impacto desses eventos na perspectiva de Marx pode ser comprovado pelo fato de, em $O$ Capital, ele tomar justamente os estados sulistas da União Americana e os principados danubianos do Império Czarista como ilustração histórica das conseqüências do entrelaçamento dos países não capitalistas no mercado mundial. Marx observa que a necessidade ilimitada de mais-trabalho, a qual deriva do próprio caráter da produção capitalista, se estende para além das fronteiras de seu modo de produção, enredando, por intermédio do mercado mundial, da anexação e da colonização, as mais vastas extensões do globo na mesma "avidez por mais-trabalho", na medida em que desloca a orientação da produção, do auto-consumo direto para a produção de valor de troca. Deste modo, a economia escravista mais ou menos patriarcal dos EUA é transformada, sob o impulso da indústria algodoeira, num sistema de exploração no qual se praticam as mais bárbaras formas de extração de sobretrabalho dos negros, enquanto, nos principados do Danúbio, a "caça direta por dias de corvéia" ameaça usurpar do camponês todos os dias do ano. Na redação aguda de $O$ Capital:

$90 \quad$ Marx e a questão russa 
Tão logo, porém, os povos, cuja produção se move ainda nas formas inferiores do trabalho escravo, corvéia, etc., são arrastados ao mercado mundial, dominado pelo modo de produção capitalista, o qual desenvolve a venda de seus produtos no exterior como interesse preponderante, os horrores bárbaros da escravatura, da servidão, etc. são coroados com o horror civilizado do sobretrabalho. Por isso, o trabalho dos negros nos Estados sulistas da União Americana preservou um caráter moderadamente patriarcal, enquanto a produção destinava-se sobretudo ao autoconsumo direto. Na medida, porém, em que a exportação de algodão tornou-se interesse vital daqueles Estados, o sobretrabalho dos negros, aqui e ali o consumo de suas vidas em 7 anos de trabalho, tornou-se fator de um sistema calculado e calculista. Já não se tratava de obter deles certa quantidade de produtos úteis. Tratava-se, agora, da produção da mais-valia. Algo semelhante sucedeu com a corvéia nos principados do Danúbio (MARX, 1988p. 182).

Podemos supor que não se trata aqui apenas da denúncia da desumanidade terrificante da combinação das formas pré-capitalistas de exploração do trabalho com a "avidez por mais-trabalho". Se levarmos em conta as observações de Marx sobre a possibilidade de a revolução européia ser esmagada pelo desenvolvimento capitalista em outras regiões muito mais vastas do globo e sobre "as grandes coisas" que se poderiam esperar do início do movimento social dos "dois lados" do mundo, não será extravagante imaginarmos que o que estava em jogo de maneira central para Marx era a ascendência global do capital como foco de conflitos multifacetados e as potencialidades abertas para a revolução social pela entrada de novas forças no proscênio histórico-mundial da confrontação global do capital, na qualidade de totalidade complexa, como mercado mundial, com a totalidade do trabalho.

O significado pleno dos "escritos tardios" de Marx sobre a Rússia apenas emerge quando situado nesse quadro mais abrangente. No final da década de 1870 , o movimento revolucionário dos narodniki chamava novamente a atenção de Marx para a Rússia. Esse movimento, malgrado seu caráter marcadamente heterogêneo, articulava-se em torno de uma "aposta” básica, qual seja de que era possível, sem passar pelos horrores do capitalismo, abrir uma via especificamente russa de transição ao comunismo, através do desenvolvimento de determinadas premissas históricas da sociedade russa. A comuna agrária russa ocupava um lugar central no alinhamento das diferentes perspectivas. A propriedade comum da terra, o hábito de deliberação coletiva, a vida comunitária, etc., característicos da comuna agrária, eram vistos como um ponto de partida viável para um desenvolvimento socialista na Rússia.

cadernos cemarx, $\mathrm{n}^{0} 5-2009 \quad 91$ 
Marx considerou seriamente as tentativas dos narodniki de analisar as possibilidades de um desenvolvimento socialista da comuna camponesa russa. Rechaçava o desdobramento pan-eslavista que essa questão assumiu em alguns autores, como Herzen, mas se referia positivamente a Tchernitchevski,

abordou, em artigos notáveis, a questão de saber se a Rússia deve começar por destruir, como pretendem seus economistas liberais, a comuna rural para passar ao regime capitalista ou se, pelo contrário, ela pode, sem experimentar as torturas deste regime, apropriar-se de todos os seus frutos, desenvolvendo suas próprias condições históricas (MARX, 1982a, p. 166).

O modo como Marx aborda essa questão é uma demonstração do caráter radicalmente anti-evolucionista de sua concepção histórica. $\mathrm{O}$ trecho citado pertence a um texto que Marx escreveu, em 1877, em resposta Mikhailovski, um dos teóricos mais importantes do narodnivestvo, que o criticara por defender uma "teoria históricofilosófica" que supunha que o capitalismo era uma fase necessária no desenvolvimento histórico de todos os povos para chegar ao comunismo. Nesse texto, Marx rechaça qualquer tentativa de extrair de sua obra a tese de que o capitalismo é uma fase necessária de um processo de desenvolvimento histórico geral regido pela força espontânea das leis econômicas, criticando Mikhailovski por

metamorfosear meu esboço histórico da gênese do capitalismo na Europa Ocidental em uma teoria histórico-filosófica da marcha geral fatalmente imposta a todos os povos, sejam quais forem as circunstâncias históricas em que se encontrem, para chegar finalmente, a esta formação econômica que assegure, juntamente com o maior impulso das forças produtivas do trabalho social, o mais completo desenvolvimento do homem. Mas ele que me perdoe: isso, ao mesmo tempo, muito me honra e muito me envergonha (MARX, 1982a, p. 167).

Na seqüência, Marx explicita sua rejeição inflexível às pretensões suprahistóricas inerentes a qualquer "teoria histórico-filosófica". Aludindo ao exemplo da Roma antiga, onde, como na Europa Ocidental moderna, houve um processo de expropriação dos camponeses e formação de grandes capitais monetários, mas onde, ao invés de trabalhadores assalariados, apareceu uma plebe ociosa e se desenvolveu, não um modo de produção capitalista, mas escravista, ele conclui:

\begin{tabular}{l|l}
\hline 92 & Marx e a questão russa
\end{tabular} 
Portanto, acontecimentos de uma surpreendente analogia, mas que ocorreram em meios históricos diferentes, levaram a resultados inteiramente distintos. Estudando cada uma dessas evoluções separadamente e comparando-as em seguida, encontraremos facilmente a chave deste fenômeno, mas nunca chegaríamos a ela com o passe-partout de uma teoria histórico-filosófica geral, cuja suprema virtude consiste em ser supra-histórica. (MARX, 1982a, p. 168)

Embora Marx, nesse texto, não ofereça conclusões concretas acerca da alternativa dos narodniki, ele explicita o marco em que a questão deve ser colocada, qual seja, no marco de um programa de investigação secular, real, empiricamente ancorada $^{2}$. Em 1881, na tentativa de esclarecer a questão para Vera Zasulitch, ele escreve uma série de esboços, através dos quais podemos ter uma idéia dos resultados a que o conduzia esse programa de investigação.

Antes de tudo, Marx trata de dissolver as dúvidas que pairam em torno da questão da abrangência das análises desenvolvidas em $O$ Capital acerca do processo da "acumulação originária". Ele explica que, ao tratar, em $O$ Capital, do processo de expropriação dos produtores como ponto de partida da metamorfose da produção feudal em produção capitalista, restringiu "expressamente a 'fatalidade histórica' deste movimento aos países da Europa Ocidental" (MARX, 1982b, p. 175). Ali se tratava, segundo ele, do "movimento ocidental", que se caracteriza pela "transformação de uma forma da propriedade privada [a propriedade privada fragmentada dos trabalhadores] em uma outra forma de propriedade privada [a propriedade privada concentrada dos capitalistas]" (MARX, 1982b, p. 176). Por conseguinte, o esquema é inaplicável ao contexto da sociedade russa, para a qual o processo da assim chamada "acumulação originária" representaria um movimento essencialmente distinto: a transformação da propriedade comum dos camponeses russos em propriedade privada. Na carta enviada a Zasulitch, ele é incisivo: “a análise feita em $O$ Capital não oferece (...) razões nem a favor nem contra a vitalidade da comuna rural" (MARX, 1982c, p. 188).

Nos esboços, Marx aduz um “único argumento sério” contra a vitalidade da comuna

2 Como fica evidente na carta enviada a Vera Zasulitch (a que se faz referência a seguir), apesar de não ter recolhido material in locu, Marx amparava sua avaliação da questão da comuna agrícola russa em uma análise dos "materiais nas fontes originais" (MARX, 1982c, p. 188). É importante reter este ponto porque a exposição de Marx nos textos que analisaremos na seqüência pode dar a impressão de que sua análise se sustenta em um enquadramento não fundamentado da comuna russa em um "tipo" mais ou menos abrangente de formação social. Aqui vale lembrar a distinção de Marx entre "exposição" e "pesquisa". A segunda não pode dispensar a análise detalhada do material.

cadernos cemarx, $\mathrm{n}^{\mathrm{O}} 5-2009 \quad 93$ 
russa: o desaparecimento das formas sociais similares em toda a Europa Ocidental. Mas, conseqüente com o "método" anunciado em sua resposta a Mikhailovski, Marx não se detém nesse ponto, indicando a necessidade de estudar "cada uma dessas evoluções separadamente e comparando-as em seguida". Assim, ele analisa a forma constitutiva da comuna agrícola e o modo de sua decadência, baseando-se nas experiências européias ou, mais propriamente, na comuna agrícola germânica e, depois, a comuna agrária russa, em seu próprio ambiente histórico, distinto daquele de seu "equivalente no Ocidente".

Marx afirma que as comunidades primitivas não podem ser incluídas em um mesmo "tipo", pois representam toda uma série de tipos que "marcam fases sucessivas de evolução" (MARX, 1983b, p. 118). A comuna rural russa pertence, segundo Marx, ao tipo mais recente da formação social arcaica: a assim chamada comuna agrícola. Essa caracterização contrapõe-se não somente às interpretações devedoras da idealização da comuna russa iniciadas pelos eslavófilos, as quais a projetavam no passado o mais longínquo, de modo a serem contemporâneas das origens da nação, mas também à caracterização de Engels (1982, p. 151), que conceituava a comuna russa apenas como forma arcaica, não como o seu tipo mais recente.

A partir das considerações de Marx sobre a "comuna agrícola", é possível compor um quadro, diferenciando-a das comunidades mais arcaicas:

\begin{tabular}{|l|l|}
\hline COMUNIDADES MAIS ARCAICAS & COMUNA AGRÍCOLA \\
\hline $\begin{array}{l}\text { Comunidade repousa sobre relações } \\
\text { naturais de parentesco entre seus } \\
\text { membros. }\end{array}$ & $\begin{array}{l}\text { Primeiro agrupamento social de homens } \\
\text { livres baseado não em laços de sangue, mas } \\
\text { em relações de vizinhança. }\end{array}$ \\
\hline $\begin{array}{l}\text { Habitação comunal como uma base } \\
\text { econômica da comunidade. }\end{array}$ & $\begin{array}{l}\text { Casa e terrenos circundantes são propriedade } \\
\text { privada familiar. }\end{array}$ \\
\hline $\begin{array}{l}\text { Propriedade comum e inalienável da terra } \\
\text { cultivável associada com a produção em } \\
\text { comum e a repartição do produto. }\end{array}$ & $\begin{array}{l}\text { Propriedade comum e inalienável da terra } \\
\text { cultivável dividida periodicamente entre } \\
\text { os membros da comuna: posse temporária } \\
\text { familiar. Produção individual (familiar) e } \\
\text { apropriação privada do produto. }\end{array}$ \\
\hline
\end{tabular}

O conjunto desses traços mais característicos da comuna agrícola descreve de maneira muito clara o dualismo inerente à constituição dessa formação social, isto \begin{tabular}{l|l} 
& \\
\hline 94 & Marx e a questão russa
\end{tabular} 
é, o conflito entre o "elemento de propriedade privada" e o "elemento comunal". Esse dualismo é responsável, segundo Marx, tanto pelas vantagens relativas da "comuna agrícola" vis-à-vis as formações mais arcaicas quanto por sua suscetibilidade à desintegração em decorrência de sua própria dinâmica interna. É preciso destacar o primeiro aspecto, pois, posteriormente, os marxistas russos, a exemplo de Plekhanov e Lenin, enfatizariam somente o segundo:

Claramente, o dualismo inerente à constituição da comuna agrária era capaz de dotá-la de uma vida vigorosa. Emancipada do vínculo forte, porém estreito, do parentesco natural, a propriedade comunal da terra e a relações sociais resultantes forneciam um fundamento sólido; enquanto a casa e o jardim como um reduto da família individual, juntamente com cultivo de pequenos lotes e apropriação privada dos seus frutos, fomentavam a individualidade numa extensão incompatível com a armação das comunidades mais primitivas. (MARX, 1983b, p. 120)

Justamente a possibilidade desse desenvolvimento da individualidade ${ }^{3}$ é que permite a Marx conceituar a comuna agrícola como o tipo mais moderno, mais elevado, da formação comunal arcaica. Esse ponto é importante, pois a produção coletiva ou cooperativa dos tipos mais arcaicos poderia sugerir um elemento de superioridade sobre a comuna agrícola. Mas, no caso das comunidades mais arcaicas, explica Marx, o caráter coletivo da produção não é um resultado da socialização da produção, mas da "fraqueza do indivíduo". (MARX, 1982b, p. 102-103)

\footnotetext{
3 Em diversos textos, Marx critica a assunção do ser humano individualizado como ponto de partida da história. Como afirma em suas anotações de 1857-58, originariamente, o ser humano aparece como um "acessório de um conglomerado humano determinado e limitado" (MARX, 1999, p. 25-26). A comunidade apresenta-se, então, como premissa natural da apropriação das condições de vida e da atividade reprodutora e objetivadora de seus membros. "O homem", escreve Marx, "só se individualiza ao longo de um [dilatado] processo histórico" (MARX, 1985a, p. 353). Um dos fatores fundamentais nessa individualização é o desenvolvimento da propriedade privada. Com a propriedade privada, a distinção entre generidade e individualidade cobra efetividade na medida em que as necessidades individuais são dotadas de existência econômica própria, à parte das necessidades da comunidade. Por outro lado, a própria propriedade privada não se desenvolve antes que, em alguma medida, o indivíduo tenha se desprendido, no decorrer do movimento histórico, dos "laços naturais" que o ligam à comunidade. No entanto, antes da sociedade burguesa, ainda que algumas individualidades possam revelar "certa categoria", não se pode pensar em "um desenvolvimento pleno e livre do indivíduo" (MARX, 1985a, p. 345), uma vez que o desenvolvimento do indivíduo é limitado por ou entra em contradição com uma "pauta estabelecida", qual seja a reprodução da comunidade sob suas condições objetivas pressupostas, lembrando que, em todas as formas sociais pré-capitalistas, a comunidade é mediadora da relação dos indivíduos com as condições objetivas do trabalho, tanto no caso em que a propriedade se apresenta como propriedade comum como no caso em que ela se apresenta em dupla forma, como propriedade do Estado e propriedade privada ou como propriedade privada e propriedade comum, complementar à primeira. A discussão deste ponto envolveria também a exposição da análise marxiana do papel do processo de troca e do trabalho assalariado na individualização. Mas isso alongaria demasiadamente esta nota de rodapé e, de qualquer modo, a complexidade do tema exige outro texto.
}

cadernos cemarx, $\mathrm{n}^{\circ} 5-2009 \quad 95$ 
A comuna agrícola não é, contudo, conceituada por Marx apenas como o tipo mais recente da formação arcaica, mas também como forma de transição, no movimento histórico da Europa Ocidental, da propriedade comunal à propriedade privada. Malgrado a propriedade privada já se insinue dentro da comuna com a propriedade privada da casa e adjacências, o fator-chave aqui, segundo Marx, é o trabalho fragmentado como fonte da apropriação privada. Foi esse fator que possibilitou uma acumulação de bens mobiliários não sujeitos ao controle comunal. Essa acumulação privada inevitavelmente dissolve a igualdade econômica e social primitiva, originando conflitos de interesses que podem minar o fundamento social da propriedade comum. Deste modo, conclui Marx (1983b:, p. 120):

como última fase da formação arcaica da sociedade, a comuna agrária é ao mesmo tempo uma fase na transição à formação secundária, e, por conseguinte, na transição da sociedadebaseadanapropriedadecomunalparaabaseadanapropriedadeprivada.Aformação secundária, claro, inclui uma série de sociedades que repousam na escravidão e servidão.

Esse esboço histórico da decadência da comuna agrícola é o prólogo necessário para Marx reformular a questão dos narodniki. A questão pertinente para Marx é se em todas as circunstâncias históricas o desenvolvimento da comuna agrícola deve seguir o caminho sugerido por esse esboço. Ora, já em sua resposta a Mikhailovski, Marx mostra que a história demonstra que é possível que "acontecimentos de uma surpreendente analogia, mas que ocorrem em meios históricos diferentes" levem a "resultados inteiramente distintos". A partir da forma constitutiva da "comuna agrícola", o que é possível afirmar, segundo Marx, é que seu dualismo inerente pressupõe a seguinte alternativa: "ou o elemento de propriedade privada que ela implica sobrepujará o elemento coletivo ou este predominará sobre aquele" (MARX, 1982b, p. 179). Cabe, então, considerar essa alternativa em relação ao meio histórico da comuna russa.

O pano de fundo da perspectiva marxiana é novamente o mercado mundial. Segundo Marx, a comuna russa de hoje ocupa uma situação sem precedente histórico, pois "é contemporânea de uma cultura superior, e ligada ao mercado mundial no qual a produção capitalista é predominante" (MARX, 1983a, p. 102). É isso o que lhe permite, teoricamente falando, desenvolver a produção coletiva ou cooperativa não mais nos moldes dos tipos mais arcaicos (algo impossível em vista do desenvolvimento da individualidade no interior da comuna russa), mas através de

\begin{tabular}{l|l}
\hline 96 & Marx e a questão russa
\end{tabular} 
uma efetiva socialização dos processos produtivos e reprodutivos sociais sobre a base da propriedade comunal:

A propriedade comunal da terra oferece a base natural para a apropriação coletiva,

e seu contexto histórico - a contemporaneidade com a produção capitalista - fornece as condições materiais já prontas para o trabalho cooperativo organizado em larga escala. Ela pode, assim, incorporar as aquisições positivas desenvolvidas pelo sistema capitalista, sem ter de suportar seu pesado tributo. (MARX, 1982d, p.121)

A possibilidade aqui delineada por Marx corresponde à resolução do dualismo inato da comuna russa no sentido do desenvolvimento do elemento coletivo e da eliminação do princípio da propriedade privada, cujo principal agente, como vimos, é o trabalho fragmentado como princípio da apropriação. Esse desenvolvimento está de acordo com a tendência geral da sociedade moderna, uma vez que a comuna russa encontrou o sistema do capital num momento em que ele já traiu sua própria incompatibilidade com as forças por ele geradas, “em uma crise que só terminará por sua eliminação, por um retorno das sociedades modernas a uma forma superior de um tipo arcaico da propriedade e da produção coletivas" (MARX, 1982b, p. 181). A quem se nega a considerar sequer a possibilidade teórica dessa evolução sob o pressuposto de determinado curso natural das coisas, Marx lembra que a própria industrialização capitalista na Rússia não teve de passar por todas as fases de incubação da indústria ocidental.

No esquema de Marx, a possibilidade de a comuna rural tornar-se o ponto de partida direto de uma evolução comunista passa pela incorporação das "condições materiais já prontas para o trabalho cooperativo organizado em larga escala". O que pode induzir a uma compreensão equivocada deste ponto é esse "já prontas", que pode ser interpretado como uma negação da necessidade de transformar as forças produtivas desenvolvidas no quadro do modo de produção capitalista. É preciso lembrar aqui que essas "condições materiais já prontas" são as condições materiais do trabalho cooperativo capitalisticamente organizado. As "condições materiais para o trabalho cooperativo em larga escala" gestadas no quadro das relações de produção capitalistas não são neutras em face destas, mas materializam a cooperação capitalista, que, quanto à forma é despótica, hierarquizada. É assim que Marx, no capítulo sobre a grande indústria, afirma que, com a maquinaria, o domínio do trabalho morto sobre o trabalho vivo, a inversão que caracteriza a relação-capital,

cadernos cemarx, $\mathrm{n}^{\mathrm{O}} 5-2009 \quad 97$ 
"ganha realidade tecnicamente palpável” (MARX, 1988b, p. 41). As tais "condições materiais já prontas para o trabalho cooperativo em larga escala" constituem, portanto, uma dimensão inseparável da subsunção real do trabalho na estrutura de comando vertical/hierárquica do capital, e, como tal, atuam inevitavelmente como um fator restritivo em relação aos objetivos da transformação socialista. Nos esboços, Marx diz que a comuna russa precisa apropriar-se dos frutos do capitalismo "sem se sujeitar ao seu modus operandi" (MARX, 1982b, p. 180). Importa completar essa colocação enfatizando que esse objetivo só pode ser realizado se "as condições materiais já prontas para o trabalho cooperativo em larga escala" apropriadas pela comuna forem transformadas simultaneamente à reconstituição do próprio processo de trabalho com base nas determinações internas cooperativa e conscientemente adotadas pelos produtores associados com o escopo de dominarem o conjunto das condições objetivas e subjetivas do processo de trabalho.

Prossigamos. Marx identifica um elemento complicador dentre as características da comuna russa e que prejudica em todos os sentidos a estratégia proposta. Trata-se de seu isolamento, da ausência de ligações entre a vida das comunas, de sua conformação como micro-cosmo localizado, o qual constitui a base natural de um despotismo central e lhe impede toda iniciativa histórica. Contudo, esse isolamento pode ser superado por um levante geral que leve à supressão desse despotismo central em prol de uma assembléia constituída por representantes escolhidos pelas próprias comunas e que funcione como órgão econômico e administrativo de seus interesses. (MARX, 1982b, p. 180, 182)

Entretanto, trata-se aqui ainda de possibilidades, enquanto a consideração da transição do trabalho parcelar ao trabalho coletivo propõe a questão da necessidade dessa transformação para os agentes sociais que podem realizá-la, isto é, os camponeses. A resposta de Marx é bem simples. O mesmo fator que fomenta entre determinadas classes os interesses favoráveis à abolição da propriedade comum qual seja, a insustentabilidade do estado atual da comuna, isto é, do estado de miséria do cultivador, que esteriliza a terra - determina a necessidade do trabalho cooperativo em larga escala. "Ademais", pergunta Marx, "o camponês que não tem o necessário para o cultivo de seus três déciatines estará em melhor situação com um número dez vezes maior de déciatines?" (MARX, 1982b, p. 182) Mesmo do ponto de vista exclusivamente "econômico", em sentido estrito, a comuna russa só pode sair do impasse colocado para o seu próprio desenvolvimento pela via da introdução do

$98 \quad$ Marx e a questão russa 
trabalho cooperativo em larga escala.

A conclusão de Marx é que a comuna russa "pode tornar-se o ponto de partida direto para o sistema econômico para o qual a sociedade moderna tende", isto é, em termos não parabólicos, para o comunismo (MARX, 1983b, p. 121). Não há muito a especular em torno do sentido do adjetivo "direto" nesse trecho. Para Marx, não é necessária uma fase capitalista de desenvolvimento para criar as pré-condições para uma transição socialista na Rússia. A comuna russa pode desenhar um caminho específico, apropriando-se dos "frutos positivos" do capitalismo para desenvolver suas próprias premissas históricas, alargando as tradições comunitárias e cooperativas e as formas de solidariedade populares, ao invés de se sujeitar ao "modus operandi" do sistema fagocitado. E o agente desse processo são os próprios camponeses, cujo modo de existência econômica não é mais sustentável a longo prazo. Chegamos à última parte das considerações de Marx.

Ele insiste em que o primeiro passo para que a comuna possa se desenvolver no sentido mencionado consiste em colocá-la em condições normais sobre sua base atual. Se se fala aqui em condições normais, deve-se entender que a comuna russa está submetida a condições anormais. O problema crucial é o que Marx chama de "conspiração de forças e de interesses poderosos" que assola a comuna russa. O Estado comparece como o pivô dessa conspiração, submetendo a comuna "a uma opressão permanente por meio das forças sociais concentradas em suas mãos" e favorecendo às custas da comuna "o desenvolvimento precoce dos meios técnicos e econômicos mais apropriados para facilitar a exploração do cultivador, ou seja, da maior força produtiva do país, e para enriquecer os "novos pilares sociais", isto é, a burguesia industrial e toda espécie de intermediários improdutivos (usurários, açambarcadores, etc.), que "sugam o sangue já escasso da comuna" (MARX, 1982b, p. 184). Assim como no seu esboço histórico da "acumulação originária", Marx chama a atenção aqui para a importância central do Estado para ativar artificialmente e para abreviar a transição para o modo de produção capitalista. De acordo com sua análise, desde a chamada "emancipação dos servos" em 1861, a comuna russa foi posta pelo Estado em uma situação econômica anormal e é esta opressão "de fora" que ativa e aguça os conflitos internos da própria comuna, marcada pelo dualismo mencionado anteriormente, colocando a comuna sob a ameaça de iminente "extinção". Assim: "O que ameaça a comuna russa não é nem a inevitabilidade histórica nem uma teoria; é a opressão do Estado e a exploração dos intrusos capitalistas que o Estado fez poderosos a expensas

cadernos cemarx, $\mathrm{n}^{\circ} 5-2009 \quad 99$ 
dos camponeses" (MARX, 1983a, p. 105).

Principalmente após a percepção de que o modo atual de explorar as massas populares não é sustentável a longo prazo, a abolição da comuna torna-se um objetivo cada vez mais consciente dos "novos pilares sociais" e do Estado, que se preparam para "desferir o golpe de misericórdia" contra a comuna. Por isso, Marx (1982b, p. 185) é taxativo:

Para salvar a comuna russa, é preciso uma revolução russa. (...) Se a revolução for feita a tempo, se ela concentrar todas suas forças, [se a parcela inteligente da sociedade russa], [se a inteligência russa concentrar todas as forças vivas do país] para assegurar um livre curso à comuna rural, logo ela se desenvolverá como um elemento regenerador da sociedade russa e como fator de superioridade sobre os países submetidos ao regime capitalista.

Após essa exposição, podemos tirar algumas conclusões. Para Marx, a realização de uma tendência histórica em desenvolvimento - seja ela a desintegração da comuna rural ou o desenvolvimento do capitalismo - depende sempre das interações objetivamente condicionadas das forças sociais envolvidas. Nesse sentido, a possibilidade de reversibilidade de tal ou qual tendência historicamente dominante não pode ser descartada aprioristicamente, mas somente no curso das ações recíprocas das forças sociais que se confrontam no terreno histórico objetivo.

A noção de alternativa é básica para a concepção histórica de Marx e sua dialética da revolução. Mas não se refere a uma escolha voluntarista entre alternativas especulativamente geradas. Trata-se, antes de tudo, de captar as contradições e os antagonismos das relações materiais de vida como campo de possíveis relações revolucionárias. Assim, Marx se concentra no fato de que a expansão global do capital não gera apenas novas possibilidades de deslocamento das contradições do capital e, deste modo, de expansão de suas fronteiras históricas relativas, mas igualmente novas possibilidades de crises mais ou menos localizadas e, com elas, o problema da resolução da questão das alternativas, colocado como necessidade prática para as forças sociais em disputa. A análise marxiana da questão social russa relaciona dialeticamente a forma constitutiva da comuna agrária em crise com o mundo em crise do sistema do capital. Como foi dito no início deste artigo, o cenário de Marx é o do despertar do movimento social no Oriente e no Ocidente como uma saída viável contra a perspectiva de um deslocamento das contradições do capital por meio de sua

\begin{tabular}{l|l}
\hline 100 & Marx e a questão russa
\end{tabular} 
expansão global. É esse o contexto da análise marxiana da "questão russa". A dupla crise - do sistema capitalista e da comuna - abre o terreno histórico para a dialética da criatividade das massas camponesas russas que têm a possibilidade de resolvê-la a seu favor através de uma revolução, que, como lemos no prefácio à edição russa de 1882 do Manifesto Comunista (Marx; Engels, s/d), pode dar o sinal para uma revolução proletária no Ocidente, de modo que ambas se complementem.

\section{Bibliografia}

ENGELS, F. “A questão social na Rússia”. In: FERNANDES, R. C. (Org.) Dilemas do socialismo: a controvérsia entre Marx, Engels e os populistas russos. Rio de Janeiro: Paz e Terra, 1982.

MARX, K. "Carta à redação de Otietchestvienniie Zapiski”. In: FERNANDES, R. C. (Org.) Dilemas do socialismo: a controvérsia entre Marx, Engels e os populistas russos. Rio de Janeiro: Paz e Terra, 1982a.

MARX, K. "Carta a Vera Zasulitch (Primeiro rascunho)". In: FERNANDES, R. C. (Org.) Dilemas do socialismo: a controvérsia entre Marx, Engels e os populistas russos. Rio de Janeiro: Paz e Terra, 1982b.

MARX, K. “Carta a Vera Zasulitch”. In: FERNANDES, R. C. (Org.) Dilemas do socialismo: a controvérsia entre Marx, Engels e os populistas russos. Rio de Janeiro: Paz e Terra, 1982c.

MARX, K. "To Engels, 11 October 1858”. In: MARX, K., ENGELS, F. Collected work. Nova York: International Publishers, 1983.

MARX, K. "The 'second' draft of a letter to Vera Zasulitch". In: SHANIN, T. (Org.) Late Marx and the Russian road: Marx and "the peripheries of capitalism". Nova York: Monthly Review, 1983a.

MARX, K. "The 'third' draft of a letter to Vera Zasulitch". In: SHANIN, T. (Org.) Late Marx and the Russian road: Marx and "the peripheries of capitalism". Nova York: Monthly Review, 1983b.

MARX, K. “To Engels, 11 January 1860”. In: MARX, K., ENGELS, F. Collected work. Nova York: International Publishers, 1985.

MARX, K. Grundrisse. México: Fondo de Cultura Econômica, vol. 1, 1985a.

cadernos cemarx, $\mathrm{n}^{\mathrm{0}} 5-2009 \quad 101$ 
MARX, K. O capital: crítica da economia politica. São Paulo: Nova Cultural, vol. $1,1988 \mathrm{a}$.

MARX, K. O capital: crítica da economia política. São Paulo: Nova Cultural, vol. $2,1988 \mathrm{~b}$.

MARX, K., ENGELS, F. (s/d). "Prefácio à edição russa de 1882 do Manifesto do Partido Comunista”. In: MARX, K., ENGELS, F. Obras escolhidas. São Paulo: Alfa-Ômega, s/d, vol. 1.

102 Marx e a questão russa 